\title{
Development of a system to produce a map of agricultural profit for Australia
}

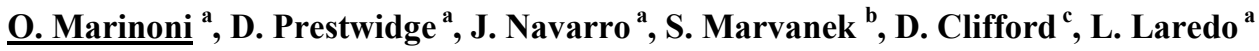 \\ ${ }^{a}$ CSIRO Ecosystem Sciences, Dutton Park, Queensland, Australia \\ ${ }^{b}$ CSIRO Land and Water, Glen Osmond, South Australia, Australia \\ ${ }^{c}$ CSIRO Mathematics and Information Sciences, Dutton Park, Queensland, Australia \\ Email: oswald.marinoni@,csiro.au
}

\begin{abstract}
Policy makers in the agricultural sector are confronted with challenges which might drive land use change and ultimately agricultural profitability to a substantial degree. The challenges include questions around climate variability, demographic changes, use of land for bio-fuel production and ensuring an increase in food production. As profitability triggers many agri-business decisions, knowledge about the existing socio-economic landscape and the economic profile of a region as well as potential impacts on profits provides useful contextual information when agricultural policies are designed. Given the upcoming challenges and their associated uncertainties it is important to ensure that a map of agricultural profit can be re-produced in a scenario and simulation setting which will allow the exploration of uncertainties around agricultural profits as well. If agricultural production information is updated, e.g. by an agricultural census, and land use information changes by the provision of an updated land use map, agricultural profits change as well and these changes can be mapped. There is however currently no flexible system in operation which allows for a consistent update of a map of agricultural profits in Australia or elsewhere. This paper describes a process that facilitates the production of maps of agricultural profit and presents a map of agricultural profit for Australia for the year 2005/06. The process involves a complex data architecture that accounts for linkages between data that have been collected by a variety of institutions across different scales such as information about land use, productivity as well as production costs and revenues. All information can be comfortably queried and query results can be forwarded for immediate processing and subsequent visualisation in a geographic information system (GIS). To facilitate the production of profit maps in the future, the system provides flexibility regarding an update of new economic information but it can also be linked to maps that show an updated distribution of land use. A map of agricultural profit on a large scale will help the understanding of profit trends in space. It will help to identify regions that have a lower economic profile and will inform decisions regarding the design of regulatory policies. As these maps are developed using national scale data, we do not recommend using the results at the farm level. The proposed system is well suited to be used in various land use management and economic scenarios and will represent a step forward regarding scenario impact assessment on agricultural profits.
\end{abstract}

Keywords: Agriculture, Profit, GIS, Remote Sensing, NDVI 


\section{INTRODUCTION}

Agriculture in Australia is an important contributor to national, state and regional economies. Historically the use of the available natural resources has however often not been sustainable (NHT 2002). Many forms of land degradation and other negative consequences have occurred including salinisation of soils, increased sediment and nutrient loads in rivers and deteriorated water quality. An important factor in targeting and designing a natural resource management planning scenario is the consideration of the existing socioeconomic landscape and the economic profile of agricultural regions provides useful contextual information. Nationally and internationally, there have been quite a few attempts across various spatial scales where agricultural profitability, yield responses or the value of agricultural land has been modeled (Bateman et al. 1999, Bastian et al. 2002, Blank et al. 2005, Kilic et al. 2005, Bryan 2009a). But there is so far no flexible system in operation which allows for a re-production of a national map of agricultural profit concurrently to the availability of new information on production and land use.

Mapping agricultural profits is difficult. The challenge is to consistently combine data from different sources (and formats) usually been collected within different spatial entities, to a target spatial entity (raster cell) that holds a profit value. Information that is required includes production costs and revenues but also how the land is used in terms of what commodities are being produced across the agricultural landscape. Table 1 shows the information that was needed used to produce the map of agricultural profit.

Table 1: Information used for the production of the profit map.

\begin{tabular}{llll}
\hline Type & Source & Spatial Entity & Coverage \\
\hline Revenues & ABS AgStats, ABARES & Statistical local area (SLA), ABARE region & National \\
Cost & Gross margin sheets, ABARES & Grower regions, ABARE regions & Local, regional \\
Water cost & National water commission NWC & Irrigation districts & Irrigation districts of Australia \\
Water use & NWC, ABS & Irrigation districts, Local government areas & Irrigation districts of Australia, \\
& & (LGA) & Local government areas (LGA) \\
Land use & ABARE-BRS & Raster cell & National \\
\hline
\end{tabular}

\section{METHODS}

\subsection{Equation to compute profit at full equity (PFE)}

Agricultural profit has been computed using the concept of profit at full equity (PFE). PFE is a measure of profit which is calculated as the revenue from the sale of agricultural commodities minus all fixed and variable costs. This concept is based on the assumption that the land is fully owned (100\% equity). The profit at full equity is a function of the gross revenue $\left(\$ \mathrm{ha}^{-1}\right.$ year $\left.^{-1}\right)$ less the production cost $\left(\$ \mathrm{ha}^{-1} \mathrm{year}^{-1}\right)$. It also captures

- $\quad$ potential multiple commodities as primary and secondary products (e.g. milk, sheep wool)

- $\quad$ variable costs such as

○ area dependent costs (i.e. seeding, fertiliser)

- quantity dependent costs (i.e. harvest, storage) and

- fixed costs such as costs for insurance, maintenance and others.

Revenues captured in this equation are farm gate revenues. In its simplified form PFE can be computed from

$$
\text { Profit at Full Equity }=\text { Price } \times \text { Quantity }- \text { Variable Costs }- \text { Fixed Costs }
$$

which in its expanded form can be written as:

$$
P F E=((P 1 \times Q 1 T R N)+(P 2 \times Q 2 \times Q 1))-((Q C \times Q 1+A C)+(W R \times W P)+(F O C+F D C+F L C))
$$

where

PFE = Profit at Full Equity; P1 - Farm Gate Price (\$/ha or \$/DSE); Q1 - Yield or Stocking Rate (\$/ha or \$/DSE); TRN - Turn-off Rate (Ratio) - (set to 1 for non-livestock commodities); P2 - Price of Secondary Product (\$/kg or \$/1); Q2 - Yield of Secondary Product (kg/DSE or 1/DSE); QC - Quantity Dependant Variable Costs (\$/t or \$/DSE); AC - Area Dependant Variable Costs (\$/ha); WR - Water Requirement of Land Use (ML/ha); WP - Water Price (\$/ML); FOC - Fixed Operating Costs (\$/ha); FDC - Fixed Depreciation Costs (\$/ha); FLC - Fixed Labour Costs (\$/ha)

As the application of this profit function is not novel it is not discussed in greater detail here. A detailed description of its parameters can be found in Bryan et al. (2009a) and Hajkowicz \& Young (2002). The resulting PFE value is mapped on a GIS raster with a raster cell resolution of $1 \mathrm{~km}$. The unit of PFE for each raster cell is $\$ /$ ha. 


\subsection{Land use map}

A prerequisite for the production of a map of agricultural profitability is a map that delineates areas of agricultural production and that shows where agricultural commodities are grown. The land use map was provided by ABARE-BRS (2010) and represents the land use for the year 2005/2006 with a spatial resolution of $1.1 \mathrm{~km}$. This map is based on an algorithm called SPREAD II (Stewart et al. 2001, Knapp et al. 2006) which like the SPREAD (Walker and Mallaawarachchi, 1998) index uses remote sensing normalised difference vegetation index (NDVI) data with control points on the land (hence with known land use and NDVI signatures) to spatially disaggregate land use using area constraints provided by agricultural census. SPREAD and SPREAD II are hence based on the different growth characteristics of land uses through a one year period. Time series NDVI data within SPREAD are used to capture the phenology of a pixel to identify commodities/land use. While SPREAD produces a single prediction of land use for each target zone, e.g. a GIS raster cell, SPREAD II uses a Bayesian Markov Chain Monte Carlo (MCMC) approach which generates a probability distribution over the possible land uses for each cell. It therefore provides a theoretically and intuitively meaningful measure of reliability (Knapp et al. 2006). SPREAD II ultimately produces probability surfaces for commodities and commodity groups which can easily be further aggregated by summation. These probability surfaces can then be used to approximate a maximum likelihood estimate of land use that is consistent with the area constraints provided by census. A more detailed explanation of the entire procedure can be found in Bryan et al. (2009b). Table 2 shows the list of SPREAD classes captured by SPREAD II.

Table 2: SPREAD classes as mapped in the latest land use map (ABARE-BRS, 2010). Explanations see text.

\begin{tabular}{cccc}
\hline \hline SPREAD ID & SPREAD descriptor & SPREAD ID & SPREAD descriptor \\
\hline 1 & Natural pastures & 14 & Cotton \\
2 & Sown pastures & 15 & Other non-cereals \\
3 & Agroforestry & 16 & Vegetables \\
4 & Fallow & 17 & Citrus \\
5 & Winter cereals & 18 & Apples \\
6 & Summer cereals & 19 & Pears \\
7 & Rice & 20 & Stone fruit \\
8 & Winter legumes & 21 & Tropical stone fruit \\
9 & Summer legumes & 22 & Nuts \\
10 & Winter oilseeds & 24 & Plantation fruit \\
11 & Summer oilseeds & 25 & Grapes \\
12 & Sugar & 26 & Grazing \\
13 & Hay & & \\
\hline \hline
\end{tabular}

\subsection{Commodities included}

Every commodity has a different national significance with regards to its economic revenue and/or the size of the area it is grown upon. The Australian Bureau of Statistics lists about 100 commodities that cover broad acre crops, vegetables, fruits and nuts. The collection of all sorts of production and cost information across all listed commodities is very time consuming and expensive. To use available resources as effectively as possible, a process was established that helped targeting the data collection effort towards "priority" commodities. In order to prioritise the data collection efforts, all commodities were ranked as a function of area and farm gate revenue as reported in the agricultural census of the year 2005/06 (ABS 2007). For the purposes of this project, commodities that make up a large portion of the total area or total revenue are given higher priority.

To infer the importance of a commodity, census information was evaluated and two importance-rankings were produced. These importance rankings were established as a function of a) the total area a commodity is grown upon and b) the economic revenue of this commodity. Based on these two rankings another list was produced where importance was a function of both area as well as economic revenue of a commodity; the higher the importance the higher the priority with regards to the data collection effort. Area refers to the area that a commodity has been grown upon in the year 2005-06 whereas the economic revenue is the value that a commodity is the farm gate revenue (local value) gained in the same year. Area and revenue information were obtained from agricultural census (ABS 2007). The importance of a commodity is computed as:

$I_{C_{x}, y}=\frac{A_{C_{x}, y}+V_{C_{x}, y}}{2}$

with 


$$
\begin{aligned}
& A_{C_{x}, y} \triangleq \frac{\text { area }(\text { ha }) \text { dedicated to commodity } x \text { in year } y}{\text { total area }(\text { ha }) \text { dedicated to all recorded commodities in year } y}[\%] \\
& V_{C_{x}, y} \triangleq \frac{\text { total value }(\$) \text { generated by commodity } x \text { in year } y}{\text { total value }(\$) \text { generated by all commodities in year } y}[\%]
\end{aligned}
$$

With $C_{x}$ : commodity $\mathrm{x} ; y$ : year for which the importance index is valid; $I_{C_{x}, y}$ : Importance of a commodity $x$ in year $y$; $A_{C_{x}, y}$ : relative area upon which commodity $\mathrm{x}$ was grown in the target year [\%]; $V_{C_{x}, y}$ : relative local value of commodity $\mathrm{x}$ in the target year [\%];

This mixed area-revenue approach was considered necessary as commodities such as vegetables, fruits and nuts generate high revenues but are grown on relatively small areas. If area was the only driver of commodity importance these economically relevant commodities would not have been considered in the analysis. Commodities were then ranked along their importance and cumulated. In total 32 commodities made up $90 \%$ of the total importance and were selected as target commodities (Figure 1).

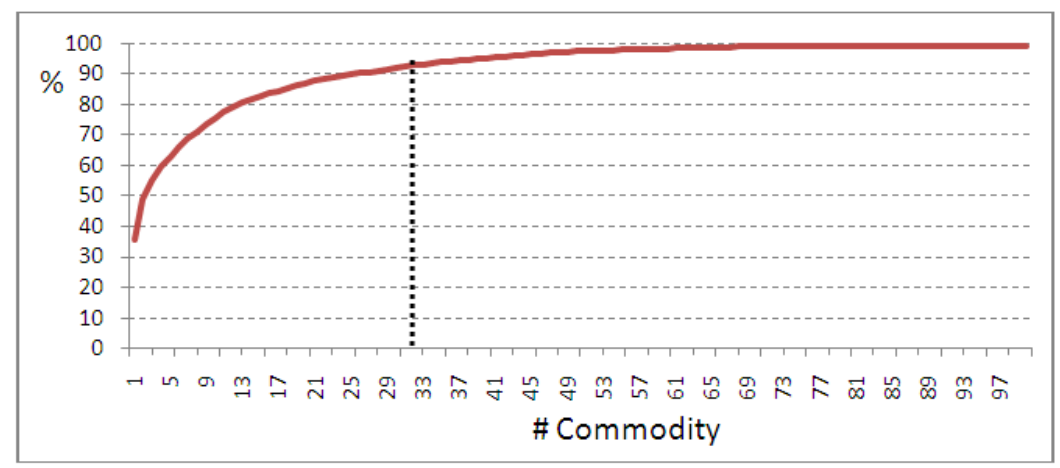

Figure 1: Cumulative graph of commodity importance (values valid for the year 2005/06).

\subsection{Livestock}

The process used to distribute livestock has been adopted from Bryan et al. (2009b). As the production statistics for livestock farms is not reported in terms of area grazed but in total numbers of livestock, livestock is spatially distributed across the mapped extent of SPREAD classes that represent pastures and grazing. The following approach has been used: In a first step, livestock production statistics were standardised to dry sheep equivalent units (DSE) (beef cattle $=8 \mathrm{DSE}$, dairy cattle $=10$ DSE and sheep $=1.5$ DSE) with DSE being a measure of energy requirements of stock commonly used in Australia to assess the carrying capacity of land. DSE units were distributed amongst the pixels deemed available for grazing in each SLA for which livestock numbers are reported. Next, livestock commodities of beef cattle, dairy cattle and sheep are allocated to the "native pasture" "open grazing" and "sown pasture" pixels using a rule-based method where commodities of beef cattle, dairy cattle or sheep are assigned to pixels according to the quality of the pasture. The quality of a pasture pixel is captured by a rank that is based on its irrigation status and land quality as inferred from SPREAD classification and the maximum monthly NDVI value. To determine the ranking of pasture pixels, the following rules were applied:

- Irrigated is superior to non-irrigated (derived from the land use grid), regardless of pasture type or NDVI.

- Sown pastures are superior to native pastures which are in turn superior to "open grazing" land (derived from the land use grid) regardless of NDVI.

- Where irrigation status and pasture type are equal, pixels with higher NDVI are superior to lower NDVI pixels.

- Where irrigation status, pasture type and NDVI are the same, rank is randomly determined.

In a last step the quota, apportioned on a DSE proportional basis for individual livestock commodities are filled. Therefore, the highest ranked pixels (best quality pasture) are allocated to dairy cattle until the dairy quota is filled. The next highest quality pixels are allocated to beef cattle with sheep being allocated to the lower quality pasture pixels.

\subsection{Revenue and cost information}

Economic data such as information regarding commodity yields (in t/ha, number of livestock) and market prices was taken from ABS 2005/2006 census data (AgStats). This information is collected on a SLA basis (Statistical Local Area) and has national coverage. Information about production cost was obtained from 
several sources including state DPI's and grower bodies that provide gross margin information. Cost information about livestock was obtained from an online database which is provided by the ABARES and MLA (Meat and Livestock Australia). This database represents the results of farm surveys which have been aggregated to an ABARES regional level. ABARES regions cover the whole of Australia.

\subsection{Process workflow}

The entire process to produce a map of agricultural profit is schematically depicted in the Figure 2.

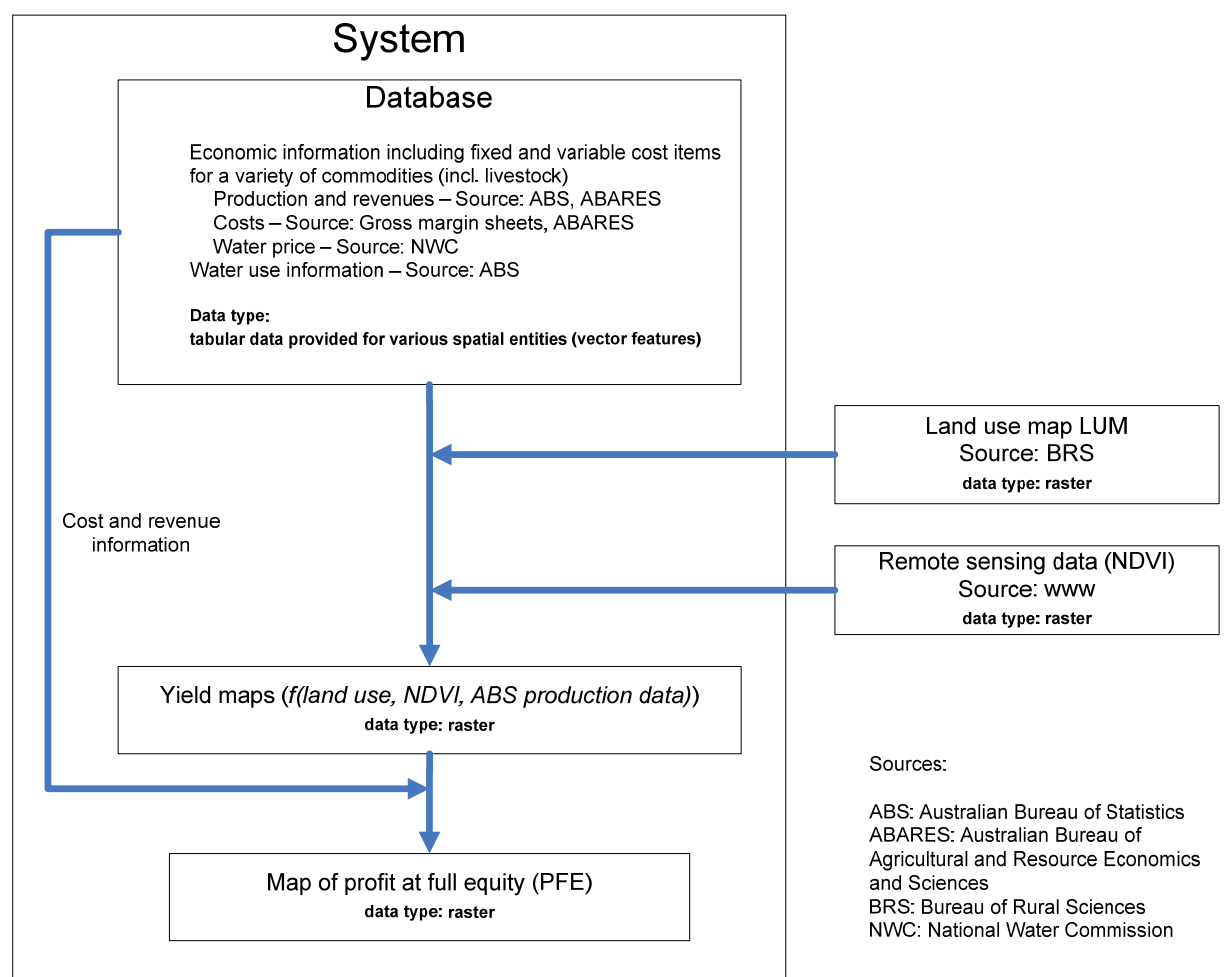

Figure 2: Schematic overview of the map production process including data types and data sources (further explanations in text).

The core of the system is a database (SQL Server) that keeps information about revenues and production cost for a variety of agricultural commodities for various spatial entities (statistical local areas (SLA) as defined by the ABS). This economic information needs to be combined with a land use layer (raster format) that tells where within the agriculturally used areas a specific commodity is grown. The remote sensing information used in the process includes the Normalised Difference Vegetation Index (NDVI). The NDVI captures the greenness of a pixel. Studies have shown that the NDVI is a good proxy for yield (Bastiaanssen \& Ali 2003). In this study, we use the NDVI to distribute reported yields across a spatial entity (SLA). For example, if the agricultural census (AgStats, conducted by ABS) reports that a specific amount [tonnes] of a commodity has been produced across a given area [ha] (or across a number of pixels on the land use map respectively) it is an over simplification to assume that the yield achieved is evenly distributed across these all pixels. Differences in the NDVI will tell where it can be most plausibly assumed where higher yields, hence ultimately higher revenues, have been achieved. All the aforementioned information is then combined through a series of database queries. These queries ultimately produce a table which is an abstract representation of the profit map. In a final step, this table is then turned into a map which can be visualised in a GIS. The system in its current state has no user friendly user interface such that items can be interactively selected, queried and immediately visualised in a GIS. Currently all queries need to be defined and run from within a SQL-Server environment. Results then need to be imported in a GIS and then further processed to produce a map. As the system is now setup and operational new census information or updated information on land use can be integrated fairly easily. Once new data are imported a succession of queries and procedures to produce the table with profit values takes about $20 \mathrm{~min}$. 


\section{PROFIT MAP OF AGRICULTURE IN AUSTRALIA FOR THE YEAR 2005/06}

Figure 3 shows the map of profit at full equity for all agriculturally used areas for the year 2005/06. Areas where PFE is negative are kept in red and orange. It is obvious that many parts of the areas of agricultural land did not make a profit in 2005/06. These areas include the vast open grazing areas of inner Australia and large areas in the north. PFE increases towards the coastal regions. The fact that large areas in the arid interior are mapped as "making a loss" does not mean that individual enterprises are not making a profit. Statistical local areas in these remote areas are very large and the spatial accuracy of the data is low. As the map is reflecting trends on a large scale it cannot reflect what is going on at an enterprise level; individual profitable enterprises will hence not show up on the map. Also, the map represents a snapshot for the year $2005 / 06$. What is was mapped as not profitable in 2005/06 can, provided climate and commodity prices are favourable, turn into profitable areas in later years.

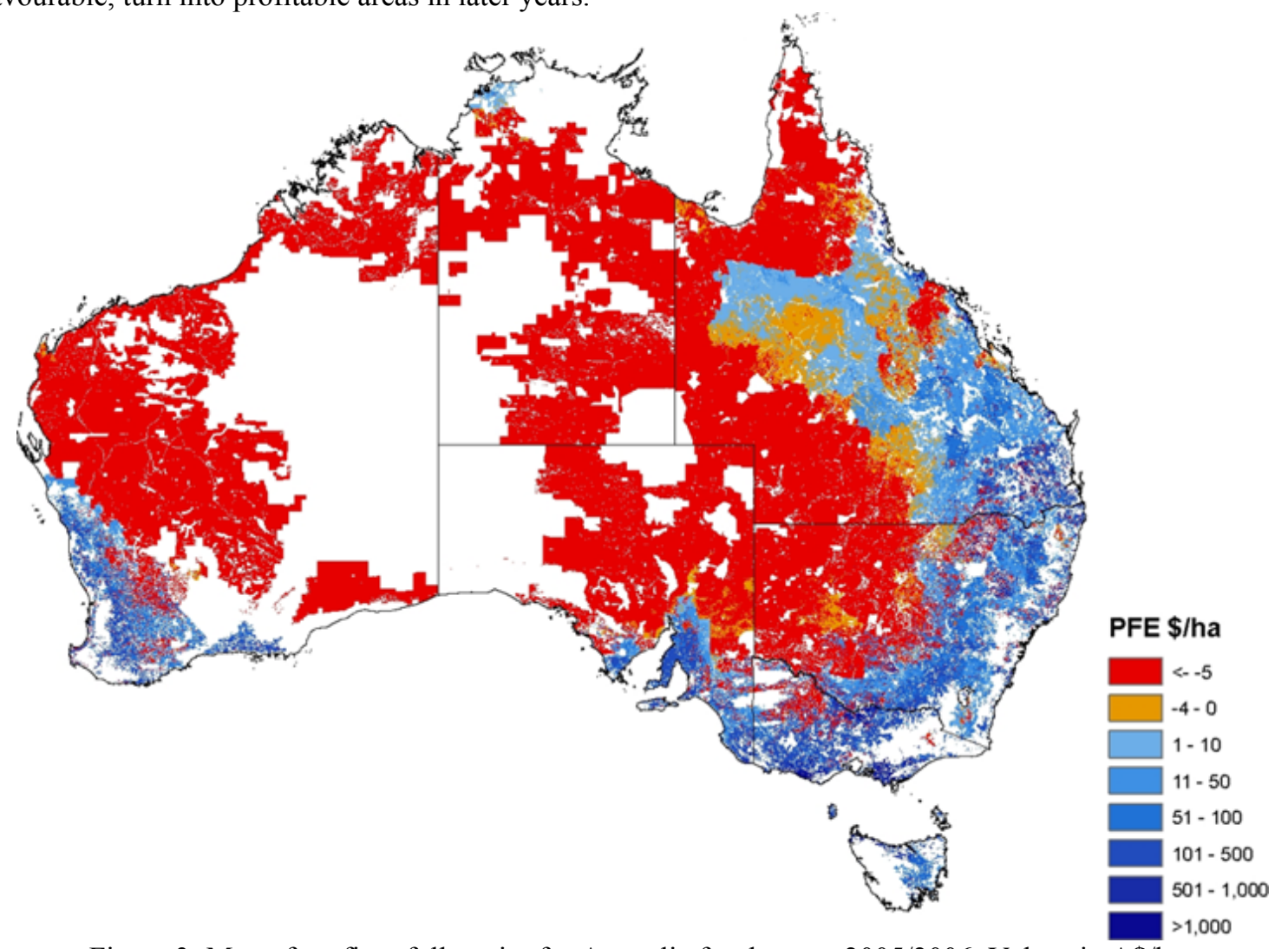

Figure 3: Map of profit at full equity for Australia for the year 2005/2006. Values in A $\$ /$ ha.

\section{DISCUSSION AND CONCLUSIONS}

Consistently linking a whole set of heterogeneous information is a key challenge in the production of a map of agricultural profit. A major issue that - if addressed - will considerably facilitate the future reproduction of this map is a more comprehensive provision of production cost information. The spatial coverage of gross margin (GM) information varies considerably across the country. Spatial gaps in cost information needed to be filled which has been realized using a simple rule based approach. While it is evident that GM information will list different items for different commodities it should be ensured that GM sheets are, for distinct commodities, as standardised across the country and as up-to-date as possible. The map of agricultural profit produced represents a snapshot for the year 2005/06. It does not capture farm rotation systems used on many Australian farms. We therefore identify a need to integrate farm system rotations in the process presented in this paper. The system is designed to accommodate maps of higher spatial resolution. While the time to compute a profit map will increase substantially with increasing resolution, we envisage using our system in a high performance computing (HPC) environment so that production times can be kept low. We consider the developed system as flexible in that we are able to update a map of agricultural profit when new census data and/or an updated land use map become available. We are aware that the data requirements to produce the profit map are substantial. It requires a land use map, detailed census information as well as information with regards to the use of resources (water) and production cost. Beyond Australia, the suggested system can hence only be applied where this information is available. 
The presented profit map has an in-built error which has not been made explicit in the results. Even though census information is provided with an associated estimate of error, quite a few components of the profit equation, for example cost information provided on gross margin data sheets, do not come with an associated estimate of error which makes an analysis of error propagation in the whole process difficult. A map that represents the error of the profit estimates is currently in development. Maps that reflect agricultural profit can now be produced more regularly for Australia. Profits can be analysed within various spatial entities such as states or catchments. Doing this over time will allow the monitoring of profit trends and will help in detecting deviations from observed trends more easily. To more comprehensively explain these deviations the profit results could be linked to the landscape and modelled with other variables, such as climate data and social and demographic information. These maps can and should also inform other decision processes that involve land use change on larger scales that could impact agricultural profit e.g. bio-carbon sequestration or bio fuel production. The presented system is also well suited to be used in scenario settings, to study for example impacts of climate change on profits. It is important to underline that the map produced is supposed to reflect trends on a regional, national and, in the case of Australia, continental scale. The map should hence be used to inform regional policies rather than policies at a farm level. We suggest conducting similar studies at catchment scales which should include more detailed farm level data and will involve a higher spatial resolution. The results of these studies would be very helpful to calibrate this national scale assessment and would also be better suited to inform farm level policies.

\section{ACKNOWLEDGMENTS}

The authors would like to thank the CSIRO Sustainable Agriculture Flagship for the funding of this research.

\section{REFERENCES}

ABARE-BRS (2010). Land Use of Australia, Version 4, 2005-06 dataset.

ABS (2007). Value of Selected Agricultural Commodities Produced, Australia, Preliminary, 2005-06.

Australian Bureau of Statistics.

http://www.abs.gov.au/AUSSTATS/abs@.nsf/Lookup/7502.0Main+Features12005-06?OpenDocument, website accessed 07.07.2011.

Bastian, C. T., McLeod, D. M., Germino, M. J., Reiners, W. A., \& Blasko, B. J. (2002). Environmental amenities and agricultural land values: a hedonic pricing model using geographic information systems data. Ecological Economics, 40, 337-349.

Bateman, I. J., Ennew, C., Lovett, A. A., \& Rayner, A. J. (1999). Modelling and mapping agricultural output values using farm specific details and environmental databases. Journal of Agricultural Economics, 50, 488511.

Bastiaanssen, W. G. M., \& Ali, S. (2003). A new crop yield forecasting model based on satellite measurements applied across the Indus Basin Pakistan. Agriculture, Ecosystems and Environment, 94, 321-340

Blank, S.C., Erickson, K.W; Moss, C.B. 2005. Profit Patterns Across American Agriculture. Journal of Agricultural and Resource Economics, 30, 2, 205-230.

Bryan, B.A., Hajkowicz, S.A., Marvanek, S., Young, M.D. (2009a). Mapping Economic Returns to Agriculture for Informing Environmental Policy in the Murray-Darling Basin, Australia. Environmental Modelling and Assessment, 14, 375-390.

Bryan, B.A., Barry, S., Marvanek S. (2009b). Agricultural commodity mapping for land use change assessment and environmental management: an application in the Murray-Darling Basin, Australia. Journal of Land Use Science. 4, 3, 131-155.

Hajkowicz, S., Young, M. (2002). Value of Returns to Land and Water and Costs of Degradation. Final Report to the National Land \& Water Resources Audit. CSIRO Land and Water Report, February 2002.

Kilic, S., Evrendilek, F., Senol, S., Celik, I. 2005. Developing a suitability index for land uses and agricultural land covers: A case study in Turkey. Environmental Monitoring and Assessment, 102, 323-335.

Knapp, S., Smart, R., Barodien, G. (2006). National Land Use Maps: 1992/93, 1993/94, 1996/97, 2000/01 and 2001/02, Version 3. National Land and Water Resources Audit, Canberra.

NHT (2002). Australians And Natural Resource Management. Natural Land \& Water resources Audit. Natural Heritage Trust. 279pp.

Stewart, J.B., Smart, R.V., Barry, S.C. \& Veitch S.M. (2001). “1996/97 land use of Australia - final report for project BRR5". National Land and Water Resources Audit, Canberra.

Walker, P.A., Mallawaarachchi, T. (1998). Disaggregating agricultural statistics using NOAA-AVHRR NDVI. Remote Sensing and the Environment 63, 112-125. 